 \\ The Clinical Physiologist
}

\author{
Section Editors: John Kreit, M.D., and Erik Swenson, M.D.
}

\section{Severe, Rapidly Reversible Hypoxemia in the Early Period after Bilateral Lung Transplantation}

\author{
Ankur Mishra $^{1}$, Robert M. Reed ${ }^{2}$, and Michael Eberlein ${ }^{1,3}$ \\ ${ }^{1}$ Department of Medicine, University of lowa Hospitals and Clinics, lowa City, lowa; ${ }^{2}$ Division of Pulmonary and Critical Care Medicine, \\ University of Maryland, Baltimore, Maryland; and ${ }^{3}$ Division of Pulmonary, Critical Care and Occupational Medicine, University of lowa \\ Hospitals and Clinics, lowa City, lowa
}

ORCID IDs: 0000-0002-2690-2163 (A.M.); 0000-0002-4681-7070 (R.M.R.); 0000-0001-6108-2546 (M.E.).

\section{In Brief}

A recipient of a bilateral lung transplant developed moderate primary graft dysfunction after extubation on Postoperative Day 1. Early on the second postoperative day she became increasingly hypertensive, and a continuous infusion of nicardipine was started. After this she developed rapidly worsening, severe hypoxemic respiratory failure requiring supplemental oxygen administered via high-flow nasal cannula. Estimated $\mathrm{Pa}_{\mathrm{O}_{2}} / \mathrm{FI}_{\mathrm{O}_{2}}$ dropped from 207 to 69. Hypoxemia responded quickly to an intervention that was based on an understanding of factors determining pulmonary gas exchange in this setting.

\section{The Clinical Challenge}

A 63-year-old woman with advanced lung disease from idiopathic pulmonary fibrosis underwent sternal-sparing, offcardiopulmonary bypass, bilateral lung transplantation. An intraoperative transesophageal echocardiogram showed both pulmonary venous anastomoses as widely patent with appropriate flow velocity by Doppler. A perfusion scan performed routinely after the surgery demonstrated homogeneous perfusion to both allografts (Figure 1).
On transfer to the intensive care unit from the operating room, the patient was hemodynamically stable and receiving lungprotective mechanical ventilation with tidal volumes set at $6 \mathrm{ml} / \mathrm{kg}$ donor predicted body weight. A chest radiograph showed mild diffuse bilateral infiltrates (Figure 2A).

At 24 hours, the ratio of $\mathrm{Pa}_{\mathrm{O}_{2}}$ to the fraction of inspired oxygen $\left(\mathrm{Pa}_{\mathrm{O}_{2}} / \mathrm{FI}_{\mathrm{O}_{2}}\right)$ was 215 , consistent with moderate primary graft dysfunction (PGD grade 2). On the first postoperative day, routine bronchoscopy showed intact bronchial anastomoses and minimal clear secretions.

The patient was extubated and was subsequently supported with supplement oxygen administered via high-flow nasal cannula (Opti-Flow; Fisher \& Paykel Healthcare, Auckland, New Zealand), initially at $0.6 \mathrm{FI}_{\mathrm{O}_{2}}$. The $\mathrm{FI}_{\mathrm{O}_{2}}$ was weaned down to 0.45 by the evening of Postoperative Day 1. At that time the estimated $\mathrm{Pa}_{\mathrm{O}_{2}} / \mathrm{FI}_{\mathrm{O}_{2}}$ was 207.

Early on the second postoperative day, the patient became progressively more hypertensive, with systolic blood pressures greater than $150 \mathrm{~mm} \mathrm{Hg}$. A continuous infusion of nicardipine was initiated. Soon after, the patient developed worsening respiratory failure with tachypnea and increased work of breathing, and her oxygen requirements rose progressively. She was titrated up to an $\mathrm{FI}_{\mathrm{O}_{2}}$ of 1.0 on the high-flow nasal cannula. Arterial blood gas measurement showed normal $\mathrm{PCO}_{2}$ and $\mathrm{pH}$ but severe hypoxemia, with an estimated $\mathrm{Pa}_{\mathrm{O}_{2}} / \mathrm{FI}_{\mathrm{O}_{2}}$ of 69 (Table 1). She remained hemodynamically stable.

A focused physical examination was significant for audible breath sounds over both lung fields. Bilateral chest tubes had normal fluctuations in the water-seal chamber with respiratory effort without any air leak. A follow-up chest radiograph showed no acute change (Figure 2B). An electrocardiogram showed no signs of myocardial ischemia.

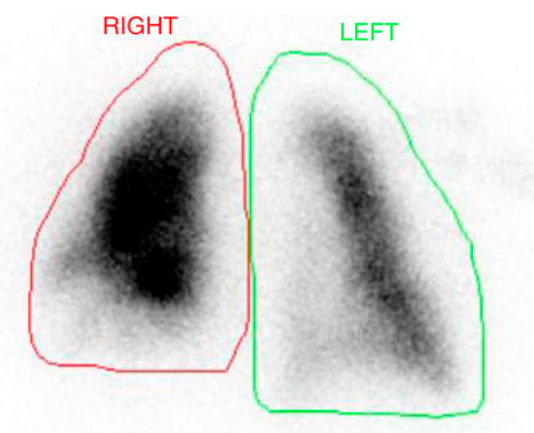

Figure 1. Perfusion scan immediately after bilateral lung transplantation. Perfusion is identified in bilateral transplanted lungs, with slight heterogeneity of perfusion at the lung base. The right-to-left perfusion ratio based on the anterior view was estimated at $60-40 \%$. These findings suggest intact vascular anastomoses without complications.

(Received in original form February 10, 2016; accepted in final form March 21, 2016)

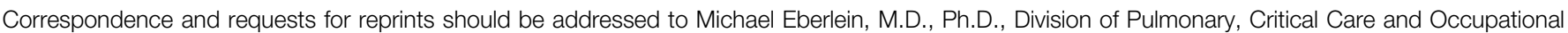
Medicine, University of lowa Hospitals and Clinics, 200 Hawkins Drive, lowa City, IA 52242. E-mail: michael-eberlein@uiowa.edu

Ann Am Thorac Soc Vol 13, No 6, pp 979-985, Jun 2016

Copyright (C) 2016 by the American Thoracic Society

DOI: 10.1513/AnnalsATS.201602-107CC

Internet address: www.atsjournals.org 
A

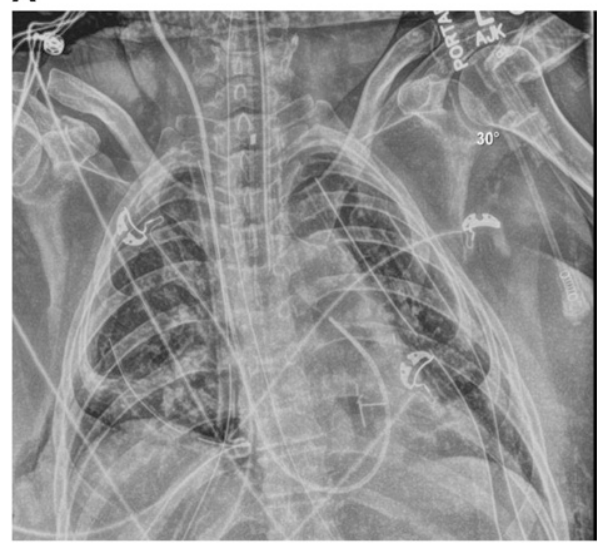

B

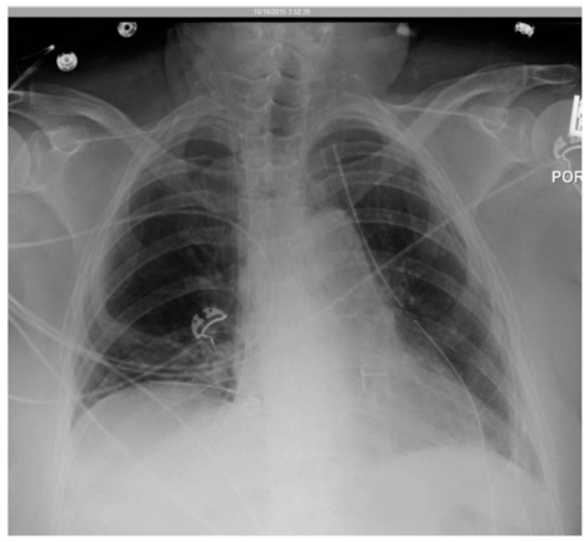

Figure 2. (A) Chest radiograph performed immediately after transplantation, showing mild diffuse bilateral infiltrates, consistent with moderate primary graft dysfunction. (B) Subsequent chest radiograph, showing no acute changes.

Table 1. Vital signs and other objective data before, during, and after nicardipine infusion

\section{\begin{tabular}{cc} 
Postoperative Day 2 \\
\hline $00: 00-01: 00$ h & $03: 00-04: 00$ h $\quad 05: 00-07: 00 ~ h$
\end{tabular}}

Temperature, ${ }^{\circ} \mathrm{C}$

Heart rate, beats/min

$\mathrm{BP}(\mathrm{mm} \mathrm{Hg})$, SBP/DBP

PAS/PAD

PCWP, $\mathrm{mm} \mathrm{Hg}$

CVP, $\mathrm{mm} \mathrm{Hg}$

$\mathrm{Cl}$ (thermodilution), $\mathrm{L} / \mathrm{min} / \mathrm{m}^{2}$

$\mathrm{FlO}_{\mathrm{O}_{2}}$

$\mathrm{pH}$, arterial

$\mathrm{PCO}_{2}$ (arterial), $\mathrm{mm} \mathrm{Hg}$

$\mathrm{PO}_{2}$ (arterial), $\mathrm{mm} \mathrm{Hg}$

$\mathrm{Pa}_{\mathrm{O}} / \mathrm{Fl}_{\mathrm{O}}$ ratio

Nicardipine infusion rate, $\mathrm{mg} / \mathrm{h}$

\begin{tabular}{ccc}
37.1 & 36.7 & 36.6 \\
85 & 94 & 70 \\
$139 / 68$ & $136 / 61$ & $110 / 57$ \\
$37 / 13$ & $37 / 12$ & $28 / 11$ \\
13 & - & 13 \\
3 & 8 & 3 \\
2.4 & - & 2.29 \\
0.45 & 1 & 0.45 \\
7.39 & 7.43 & 7.44 \\
36 & 39 & 39 \\
93 & 69 & 110 \\
207 & 69 & 240 \\
0 & 3 & 0 \\
\hline
\end{tabular}

Definition of abbreviations: $\mathrm{BP}=$ blood pressure; $\mathrm{Cl}=$ cardiac index; $\mathrm{CVP}=$ central venous pressure; $\mathrm{DBP}=$ diastolic blood pressure; $\mathrm{PAD}=$ pulmonary artery diastolic pressure; $\mathrm{PAS}=$ pulmonary artery systolic pressure; PCWP = pulmonary capillary wedge pressure; SBP = systolic blood pressure. 


\section{Clinical Reasoning}

Sudden, severe hypoxemia on the second postoperative day after lung transplantation has a broad differential diagnosis. This includes causes directly related, and indirectly related, to the surgery (Table 2). Directly related causes include PGD, bronchial anastomotic complications, pulmonary venous and arterial vascular anastomotic complications, and cardiac tamponade. Indirectly related causes include pulmonary embolus, pneumothorax, atelectasis, mucus plugging, pneumonia/ sepsis, pulmonary edema, and acute myocardial infarction. Table 2 highlights key symptoms and signs of these conditions and the pertinent negative findings relating to the patient in our case vignette.
In the absence of these usual causes of hypoxemia, we considered the relationship between starting nicardipine and the development of rapidly progressive, severe hypoxemia (Table 1). Nicardipine inhibits hypoxic pulmonary vasoconstriction (1-6). Hypoxic pulmonary vasoconstriction is a reflex contraction of vascular smooth muscle in the pulmonary circulation in the setting of alveolar hypoxia. Hypoxic pulmonary vasoconstriction is an important compensatory mechanism to minimize ventilation-perfusion $(\dot{\mathrm{V}} / \dot{\mathrm{Q}})$ mismatching and shunting that can occur in the situation of heterogeneous or focal pulmonary pathology, as shown in Figure 3. We reasoned that in a patient with PGD, inhibition of hypoxic pulmonary vasoconstriction by nicardipine might be responsible for the acute onset of her severe hypoxemia.

\section{The Clinical Solution}

Nicardipine was stopped, and our patient was given furosemide and administered noninvasive mechanical ventilation. Within 1 hour, the $\mathrm{FI}_{\mathrm{O}_{2}}$ was reduced from 1.0 to 0.45 and the estimated $\mathrm{Pa}_{\mathrm{O}_{2}} / \mathrm{FI}_{\mathrm{O}_{2}}$ increased from 69 to 240 . Over the next few days, allograft function continued to improve, and the patient was weaned to ambient air by Postoperative Day 6 .

On the basis of the rapid improvement in the patient's hypoxemia after the discontinuation of nicardipine, we reasoned that inhibition of hypoxic pulmonary vasoconstriction by nicardipine was the main contributor to the severe and rapidly reversible hypoxemic respiratory failure. The underlying heterogeneous/focal pulmonary dysfunction from moderate PGD was a precondition leading to $\dot{\mathrm{V}} / \dot{\mathrm{Q}}$

Table 2. Differential diagnosis for acute, severe hypoxic respiratory failure in the early post-lung transplantation period

\section{Differential Diagnosis}

Primary graft dysfunction

Pulmonary venous anastomotic obstruction

Pulmonary arterial anastomotic obstruction

Bronchial anastomotic dehiscence

Phrenic nerve injury

Torsion of the allograft

Hyperacute rejection/acute rejection

Cardiac tamponade

Pneumonia/sepsis

Aspiration

Volume overload

Mucus plugging/atelectasis

Pulmonary embolism

Myocardial infarction

Cardiac shunt (PFO)

Methemoglobinemia

TRALI

Typical Presentation

Pertinent Negative Findings in Patient

\section{Directly Related to Surgery}

Diffuse alveolar infiltrates on CXR with hypoxemic respiratory failure

Pulmonary edema refractory to diuresis on the Responded to diuresis site of anastomotic problem

Pulmonary hypertension, signs of right heart failure, systemic hypotension

Substantial air leak from chest tube

Hypoventilation, CXR reveals atelectasis or hemidiaphragm elevation

Acute pulmonary hypertension, CXR with alveolar infiltrates with consolidation

Nonspecific findings of fever, cough, shortness of breath. Progressively worsening alveolar infiltrates on the CXR

Elevated CVP, systemic hypotension, equalization of diastolic pressures, low cardiac index

\section{Indirectly Related to Surgery}

Fever, abnormal lobar infiltrate

Focal pulmonary alveolar infiltrates on CXR

Diffuse fluffy infiltrates, elevated CVP, elevated filling pressures

Opacity of a segment or part of the lung

Tachycardia, systemic hypotension if massive, pulmonary hypertension

EKG changes, troponin elevation

Hypoxemia unresponsive to increasing $\mathrm{FIO}_{2}$

Cyanosis, blood shows chocolate-brown color Dyshemoglobinemia: $\mathrm{Sp}_{\mathrm{O}_{2}}$ low, $\mathrm{Pa}_{\mathrm{O}_{2}}$ is normal or high

Lung injury after blood product exposure
CXR with no change in mild diffuse infiltrates

CVP normal, PA pressures normal, systemic hypertension

No air leak from the chest tube

Normal $\mathrm{PCO}_{2}$. Negative for these findings on CXR

Normal PA pressures, CXR without these findings

Rapid clinical improvement without specific treatment for acute rejection

Normal CVP, systemic hypertension, cardiac index within normal limits

No fever, no lobar infiltrate on CXR

No focal pulmonary alveolar infiltrates on CXR

Only mild diffuse infiltrates, normal filling pressures

No focal opacity seen on CXR. Bronchoscopy $24 \mathrm{~h}$ previously with patent airways

No tachycardia. Systemic hypertension. No pulmonary hypertension

No ischemic EKG changes, negative troponins

No PFO on pretransplantation TTE with bubble study or intraoperative TEE

No cyanosis, no dyshemoglobinemia

No blood product exposure

Definition of abbreviations: $\mathrm{CXR}=$ chest radiograph; $\mathrm{CVP}=$ central venous pressure; $\mathrm{PA}=$ pulmonary artery; $\mathrm{PFO}=$ patent foramen ovale; $\mathrm{Sp} \mathrm{O}_{2}=$ arteria oxyhemoglobin saturation; TEE = transesophageal echocardiogram; TRALI = transfusion-related acute lung injury; TTE = transthoracic echocardiogram. 

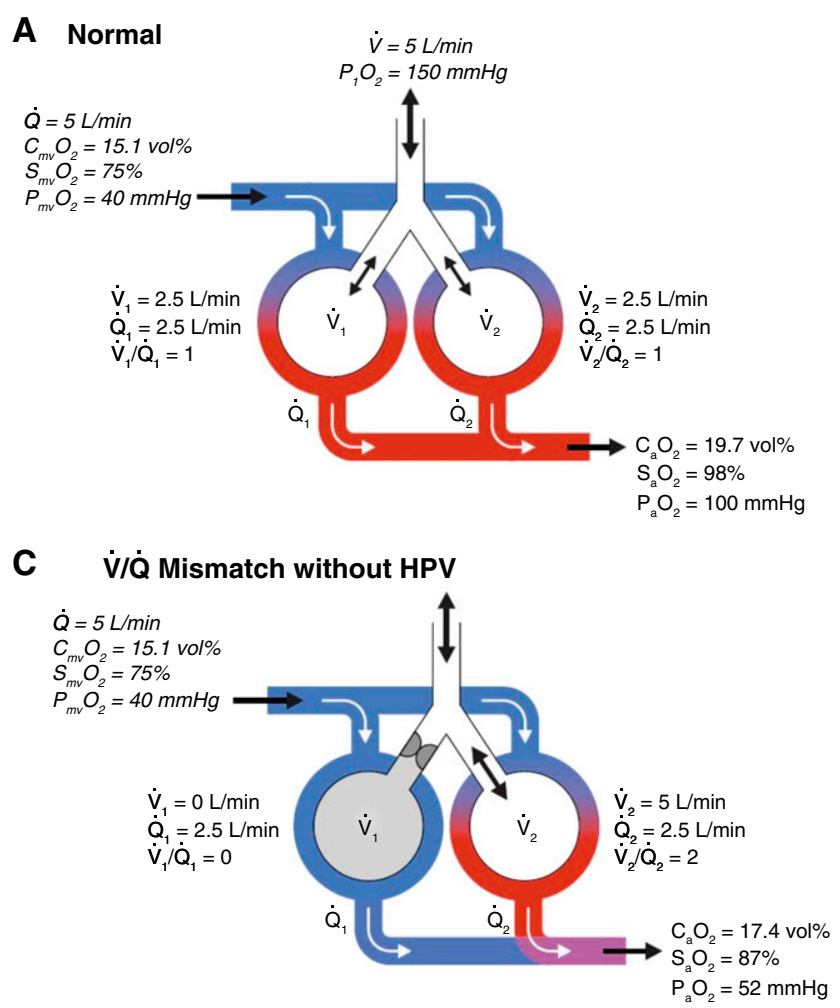

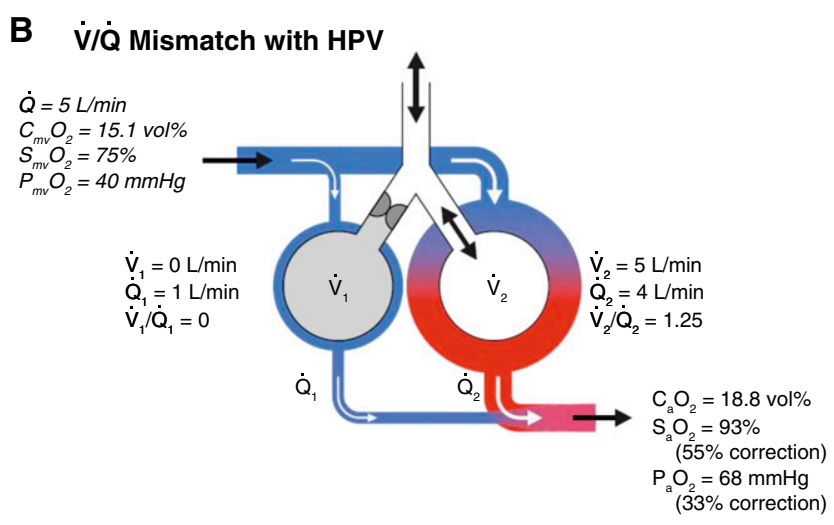

D $\quad \dot{V} / Q \bar{Q}$ Mismatch without HPV and low mixed venous PO2

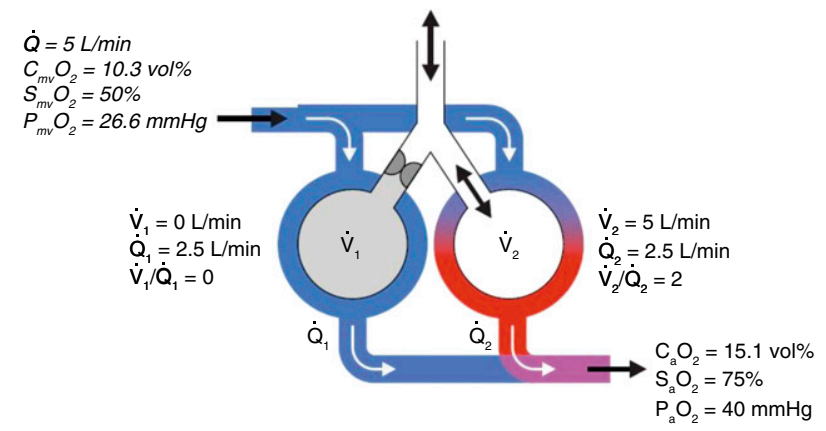

Figure 3. Effects of ventilation-perfusion $(\dot{V} / \dot{Q})$ relationships on oxygen exchange in a two-compartment lung under $(A)$ ideal or perfect conditions, (B) $\dot{V} / \dot{Q}$ mismatch (absent ventilation in one compartment with $\dot{V} / \dot{Q}=0$, consistent with right-to-left shunt) with hypoxic pulmonary vasoconstriction, (C) $\dot{V} / \dot{Q}$ mismatch (absent ventilation in one compartment with $\dot{V} / \dot{Q}=0$, consistent with right-to-left shunt) without hypoxic pulmonary vasoconstriction, and $(D) \dot{V} / \dot{Q}$ mismatch (absent ventilation in one compartment with $\dot{V} / \dot{Q}=0$, consistent with right-to-left shunt) without hypoxic pulmonary vasoconstriction in the setting of low mixed venous $\mathrm{Po}_{2}$. Values for total ventilation $(\dot{\mathrm{V}})$, inspired oxygen tension $\left(\mathrm{P}_{\mathrm{O}_{2}}\right)$, total cardiac output $(\dot{\mathrm{Q}})$, and mixed venous oxygen concentration $\left(\mathrm{Cmv}_{\mathrm{O}_{2}}\right)$, tension $\left(\mathrm{Pmv}_{\mathrm{O}_{2}}\right)$, and hemoglobin saturation $\left(\mathrm{Smv}_{\mathrm{O}_{2}}\right)$ shown in $(A)$ were the same for all conditions, except for $(D)$, as indicated. Compartmental ventilation $\left(\dot{V}_{1}, \dot{V}_{2}\right)$, perfusion $\left(\dot{Q}_{1}, \dot{Q}_{2}\right)$, ventilation-perfusion ratio $\left(\dot{V}_{1} / \dot{Q}_{1}, \dot{V}_{2} / \dot{Q}_{2}\right)$, the resulting systemic arterial oxygen concentration $\left(C a_{2}\right.$, calculated as the perfusion-weighted mean of the oxygen concentrations in blood flowing from each compartment), and corresponding systemic arterial oxyhemoglobin saturation $\left(\mathrm{Sa}_{\mathrm{O}_{2}}\right)$ and oxygen tension $\left(\mathrm{Pa}_{\mathrm{O}_{2}}\right)$ are also indicated for each condition. For simplicity, oxygen concentrations were calculated as the product of hemoglobin concentration $(15 \mathrm{~g} / \mathrm{dll}$ ), hemoglobin oxygen-binding capacity ( $1.34 \mathrm{vol} \% \mathrm{per} \mathrm{g} / \mathrm{dll})$, and oxyhemoglobin saturation, and ignore the concentration of oxygen physically dissolved in plasma, which would be small at these oxygen tensions. Vol\% indicates milliliters of oxygen (STPD) per $100 \mathrm{ml}$ of blood. Reproduced by permission from Reference 1. HPV = hypoxic pulmonary vasoconstriction.

mismatch. Nicardipine, by inhibiting hypoxic pulmonary vasoconstriction, likely caused severe worsening of the $\dot{V} / \dot{Q}$ mismatch and shunting in the most dysfunctional pulmonary units.

\section{The Science behind the Solution}

\section{What Is Hypoxic Pulmonary Vasoconstriction, and Why Is It Useful?}

Hypoxic pulmonary vasoconstriction is a reflex contraction of vascular smooth muscle cells in both the arterioles and venules of the lungs, initiated by a reduction in local $\mathrm{PO}_{2}$ engendered in most settings by alveolar hypoxia $(1,2)$. Because it is not solely dependent on autonomic input, hypoxic pulmonary vasoconstriction is still present in the denervated, transplanted lung (3), similarly as in a normal lung.

Hypoxic pulmonary vasoconstriction is fundamentally different from the response to hypoxia in the systemic circulation, which typically leads to vasodilation. In 1946 von Euler and Liljestrand were the first to suggest that hypoxic pulmonary vasoconstriction leads to "an adequate distribution of the blood through the various parts of the lungs according to the efficiency of ventilation" (4). They proposed that hypoxic pulmonary vasoconstriction is a mechanism that optimizes oxygenation of blood in the lung by matching local perfusion to local ventilation.
Hypoxic pulmonary vasoconstriction is modulated by carbon dioxide (5). The presence of hypercapnia with acidosis augments hypoxic pulmonary vasoconstriction and can further improve ventilation and perfusion matching $(5,6)$. Thus, a key function of hypoxic pulmonary vasoconstriction is to reduce the impact of $\dot{\mathrm{V}} / \dot{\mathrm{Q}}$ mismatch on gas exchange, as shown in Figure 3.

In Figure 3 the lung is shown as a simple two-compartment model (1). Figure $3 \mathrm{~A}$ shows an ideal or perfect lung breathing ambient air with matched ventilation and perfusion in both compartments $(\dot{\mathrm{V}} / \dot{\mathrm{Q}}=1)$, with a resulting arterial $\mathrm{PO}_{2}$ of $100 \mathrm{~mm} \mathrm{Hg}$ and an arterial oxyhemoglobin saturation of $98 \%$. In Figure $3 \mathrm{~B}$ one compartment is shown with 
completely obstructed airflow and absence of alveolar ventilation. With hypoxic pulmonary vasoconstriction intact, a reduced perfusion of the obstructed compartment occurs. In this example the blood flow to the obstructed compartment is, via hypoxic pulmonary vasoconstriction, reduced from 2.5 to $1 \mathrm{~L} / \mathrm{min}(60 \%$ reduction).

Because of the blood flow diversion, via hypoxic pulmonary vasoconstriction in the obstructed compartment, the perfusion to the nonobstructed compartment increases. The nonobstructed, well-ventilated compartment now receives $80 \%$ of the total blood flow and maintains a $\dot{\mathrm{V}} / \dot{\mathrm{Q}}$ of 1.25 , whereas the obstructed compartment with a $\dot{\mathrm{V}} / \mathrm{Q}$ of 0 receives only $20 \%$ of the total blood flow (Figure 3B). Thus, despite a $\dot{V} / \dot{Q}$ of 0 in one of the two compartments, the arterial $\mathrm{PO}_{2}$ is preserved at $68 \mathrm{~mm} \mathrm{Hg}$ and an arterial oxyhemoglobin saturation of 93\%.

Figure 3C again shows one compartment with completely obstructed airflow and absence of alveolar ventilation; however, it now demonstrates the effect of absent hypoxic pulmonary vasoconstriction. Thus, with equal blood flow from each compartment, the arterial $\mathrm{PO}_{2}$ is reduced to $52 \mathrm{~mm} \mathrm{Hg}$ and an arterial oxyhemoglobin saturation of $87 \%$

(Figure 3C).

The impact of a falling mixed venous $\mathrm{PO}_{2}$, which will occur as arterial saturation and oxygen content fall, is shown in Figure 3D. It again shows one compartment with completely obstructed airflow and the absence of alveolar ventilation. It demonstrates the greater effect of absent hypoxic pulmonary vasoconstriction in the setting of a low mixed venous $\mathrm{PO}_{2}$ of $26.6 \mathrm{~mm} \mathrm{Hg}$ (oxyhemoglobin saturation of $50 \%)$. Again, with equal blood flow from each compartment because of the absent hypoxic pulmonary vasoconstriction, there is a greater reduction in arterial $\mathrm{PO}_{2}$, now to $40 \mathrm{~mm} \mathrm{Hg}$, and the arterial oxyhemoglobin saturation is reduced now to $75 \%$.

\section{Cellular Mechanisms of Hypoxic Pulmonary Vasoconstriction}

The ability of small pulmonary vessels to contract in response to hypoxia resides in the pulmonary arterial smooth muscle cells (1). The three important components of pulmonary arterial smooth muscle cells involved in mediating hypoxic pulmonary vasoconstriction are as follows: the cell membrane, the sarcoplasmic reticulum, and the contractile apparatus.

At the smooth muscle cell membrane, hypoxic pulmonary vasoconstriction has been postulated to be mediated through L-type voltage-gated calcium channels. At resting membrane potential (about $-60 \mathrm{mV}$ ) these calcium channels are mostly closed. Hypoxia inhibits outward potassium current causing membrane depolarization (Figure 4) (7). If hypoxia-mediated cell membrane depolarization occurs, the $\mathrm{L}$ voltage-gated calcium channels open, causing the entry of calcium, which then leads to further release of calcium from the sarcoplasmic reticulum. The intracellular release of calcium activates the contractile apparatus, leading to vasoconstriction. Inhibition of potassium current and subsequent cell membrane depolarization is proportional to the severity of hypoxia and is more prominent in the smaller, low-resistance arteries than in the larger pulmonary arteries (7).

\section{Pharmacologic Inhibition of Hypoxic Pulmonary Vasoconstriction}

Inhibition of hypoxic pulmonary vasoconstriction by calcium channel blockers was demonstrated in the isolated lung and in animal models (8). Nicardipine is a potent inhibitor of hypoxic pulmonary vasoconstriction (Figure 5) (8). Simonneau and colleagues demonstrated that

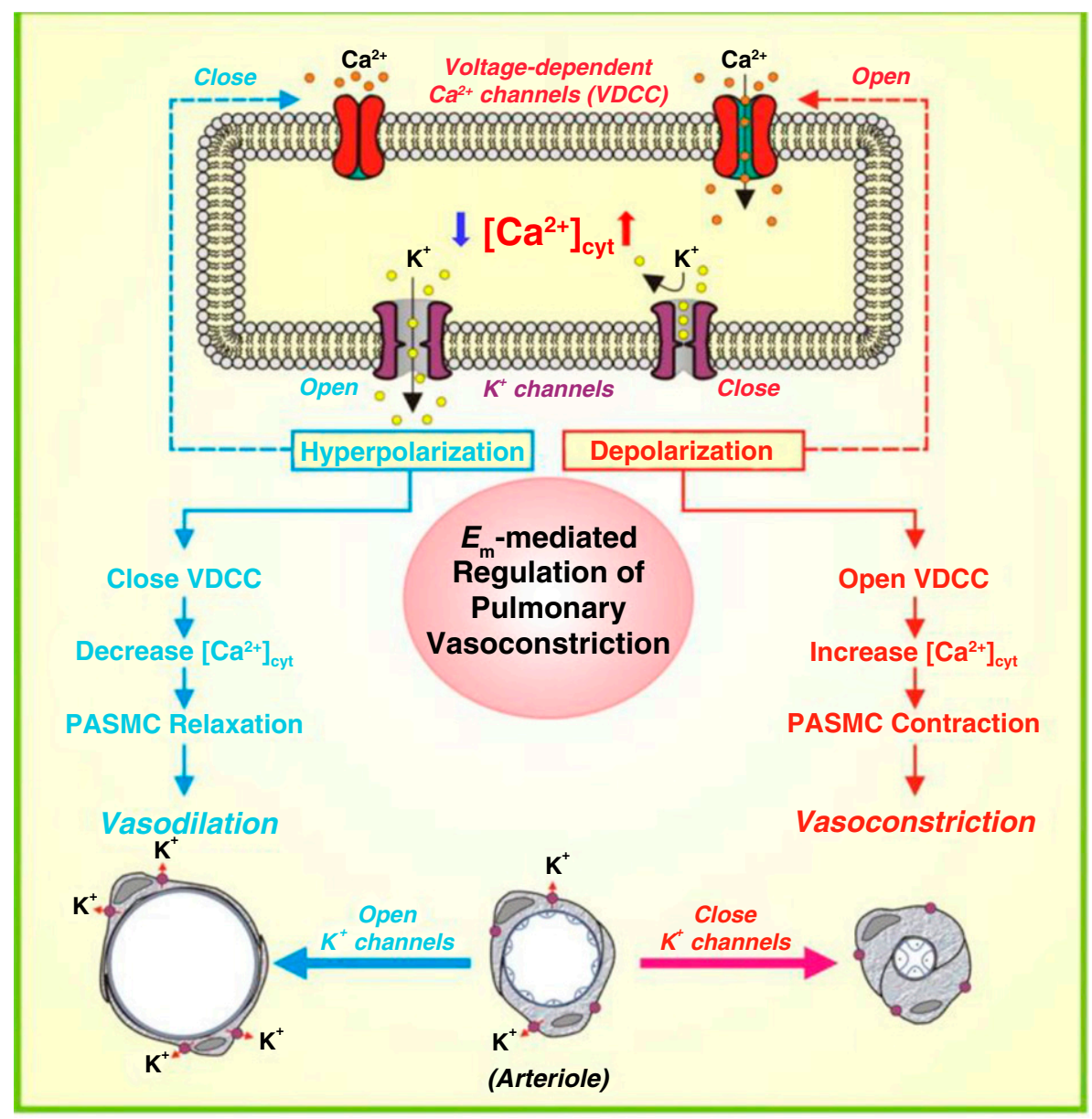

Figure 4. The role of $\mathrm{K}^{+}$channels and voltage-dependent $\mathrm{Ca}^{2+}$ channels in membrane depolarization (membrane potential, $\mathrm{Em}$ ) and pulmonary vasoconstriction. When $\mathrm{K}^{+}$channels are closed, the resulting membrane depolarization opens voltage-dependent $\mathrm{Ca}^{2+}$ channels (VDCCs), promotes $\mathrm{Ca}^{2+}$ influx, increases $\left[\mathrm{Ca}^{2+}\right]$ in the cytosol, and causes vasoconstriction. When $\mathrm{K}^{+}$ channels are activated the resulting membrane hyperpolarization closes VDCCs, inhibits agonistmediated $\mathrm{Ca}^{2+}$ influx, and causes vasodilation. $\left[\mathrm{Ca}^{2+}\right]_{\text {cyt }}=\mathrm{Ca}^{2+}$ concentration in the cytosol; $\mathrm{PASMC}=$ pulmonary artery smooth muscle cell. Reproduced by permission from Reference 4. 


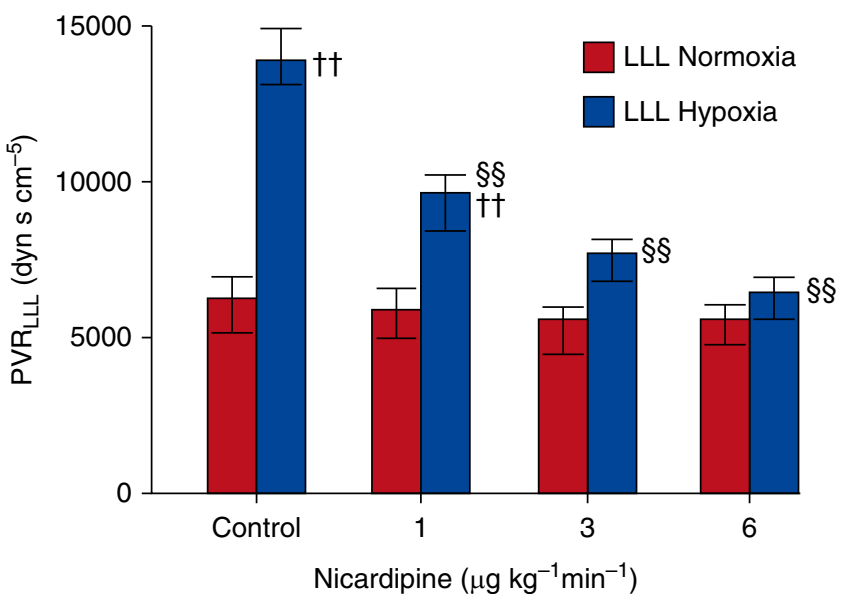

Figure 5. Pulmonary vascular resistance (PVR) during left lower lobe (LLL) normoxia and LLL hypoxia with and without nicardipine at 1,3 or $6 \mu \mathrm{g} / \mathrm{kg} / \mathrm{min}$. Data are expressed as means $\pm \operatorname{SEM}(n=7)$. Significant change from LLL normoxia at same dose of nicardipine: ${ }^{\dagger \dagger} P<0.01$. Significant change from control LLL hypoxia: ${ }^{\S} P<0.01$. Reproduced by permission from Reference 8. nifedipine, a potent calcium channel blocker, inhibits hypoxic pulmonary vasoconstriction in humans with respiratory disease from chronic airflow obstruction (9). Nifedipine also caused a significant lowering of arterial $\mathrm{PO}_{2}$ from $45 \pm 2$ to $42 \pm 2 \mathrm{~mm} \mathrm{Hg}(P<0.01)(7)$.

Table 3. Pharmacologic inhibition of hypoxic pulmonary vasoconstriction

\section{Vasoactive Drug}

Calcium channel blockers

Acetazolamide

Sodium nitroprusside

Nitroglycerine

Phosphodiesterase inhibitors

ACE inhibitors

Endothelin antagonists

Halothane

Hydralazine

Angiotensin receptor blockers

Leukotriene antagonists and receptor blockers

$\beta_{2}$-Receptor agonists Definition of abbreviations: $\mathrm{ACE}=$ angiotensin-converting enzyme; HAPE = high-altitude pulmonary
edema.
This was, however, compensated by the increased cardiac output caused by the systemic vasodilatory effect of nifedipine, so that the quantity of oxygen transported per unit of time by the arterial blood actually rose slightly $(P<0.05)$.

\section{Effect on Hypoxic Pulmonary Vasoconstriction} pulmonary vasoconstriction. Nifedipine is used treat and prevent HAPE in humans

Animal and human studies $\rightarrow$ impair hypoxic pulmonary vasoconstriction

Vasodilator $\rightarrow$ impairs hypoxic pulmonary vasoconstriction

Vasodilator $\rightarrow$ impairs hypoxic pulmonary vasoconstriction

Attenuate hypoxic pulmonary vasoconstriction response. Sildenafil in particular is used to prevent HAPE and in the treatment of pulmonary arterial hypertension

Reduce hypoxic pulmonary vasoconstriction

Attenuate hypoxic pulmonary

vasoconstriction. Drugs such as bosentan and sitaxsentan

Potent inhibitor of hypoxic pulmonary vasoconstriction

Vasodilator $\rightarrow$ impairs hypoxic pulmonary vasoconstriction

Reduce hypoxic pulmonary vasoconstriction

Inhibitors of hypoxic pulmonary vasoconstriction

Attenuate hypoxic pulmonary vasoconstriction an important mechanism to optimize oxygenation of blood in the lung by matching local perfusion to local ventilation. Inhibiting hypoxic pulmonary vasoconstriction in the setting of heterogeneous or focal pulmonary pathology can increase shunt flow and $\dot{\mathrm{V}} / \dot{\mathrm{Q}}$ mismatch and contribute to significant

delivery from the increased cardiac output the mixed venous $\mathrm{PO}_{2}$ was unchanged by nifedipine (baseline, $30 \pm 1 \mathrm{~mm} \mathrm{Hg}$; during nifedipine, $30 \pm 2 \mathrm{~mm} \mathrm{Hg}$ ). Without the effect on the systemic circulation, the lower arterial $\mathrm{PO}_{2}$ caused by nifedipine would have also lowered the mixed venous $\mathrm{PO}_{2}$, and this would have increased the fall in arterial oxygen tension caused by nifedipine, as highlighted in Figure 3D.

There are several case reports of calcium channel blocker-induced hypoxemia in patients with underlying pulmonary pathology. However, we are not aware of previous case reports of hypoxemia caused by administration of a calcium channel blocker to a patient who had undergone lung transplantation. There are two reports of nimodipineinduced acute hypoxemia in patients with traumatic subarachnoid hemorrhage complicated by respiratory failure $(10,11)$. In addition, there is a report of a 55-year-old man with moderate hypoxemic respiratory failure from lobar pneumonia, who presented with substantial worsening of his hypoxemia after intravenous administration of nicardipine (12), as in our patient.

In addition to calcium channel blockers, there are a number of other vasoactive drugs that can inhibit hypoxic pulmonary vasoconstriction (Table 3 ). Vasodilators, like sodium nitroprusside, can inhibit hypoxic pulmonary vasoconstriction. A report on a 61-year-old patient with chronic obstructive pulmonary disease undergoing mitral valve repair showed a temporal relationship between starting sodium nitroprusside and severe hypoxemia (13). This report highlighted that low mixed-venous oxyhemoglobin saturations amplify the effect of pharmacologic inhibition of hypoxic pulmonary vasoconstriction (Figure 3D).

\section{Conclusion}

Hypoxic pulmonary vasoconstriction is 
worsening of hypoxemic respiratory failure. This case highlights that pharmacologic inhibition of hypoxic pulmonary vasoconstriction is an important consideration in the differential diagnosis of hypoxemia.

\section{Answers}

1. What is the most likely cause of this patient's hypoxemia?

Sudden, severe hypoxemia on the second postoperative day after lung transplantation has a broad differential diagnosis, which includes causes directly related, and indirectly related, to the surgery, as detailed in Table 2.

\section{What is the pathophysiological mechanism?}

On the basis of the rapid improvement in the patient's hypoxemia after the discontinuation of nicardipine, we reasoned that inhibition of hypoxic pulmonary vasoconstriction by nicardipine was the main contributor to the severe and rapidly reversible hypoxemic respiratory failure.
3. How would you approach the management of the hypoxemic respiratory failure in this patient?

Nicardipine was stopped to restore hypoxic pulmonary vasoconstriction, and our patient was given furosemide and administered noninvasive mechanical ventilation to improve the underlying heterogeneous/focal pulmonary dysfunction from moderate primary graft dysfunction.

Author disclosures are available with the text of this article at www.atsjournals.org.

\section{References}

1 Sylvester JT, Shimoda LA, Aaronson PI, Ward JP. Hypoxic pulmonary vasoconstriction. Physiol Rev 2012;92:367-520.

2 Swenson ER. Hypoxic pulmonary vasoconstriction. High Alt Med Biol 2013;14:101-110.

3 Robin ED, Theodore J, Burke CM, Oesterle SN, Fowler MB, Jamieson SW, Baldwin JC, Morris AJ, Hunt SA, Vankessel A, et al. Hypoxic pulmonary vasoconstriction persists in the human transplanted lung. Clin Sci (Lond) 1987;72:283-287.

4 von Euler US, Liljestrand G. Observations on the pulmonary arterial blood pressure in the cat. Acta Physiol Scand 1946;12:301-320.

5 Kregenow DA, Swenson ER. The lung and carbon dioxide: implications for permissive and therapeutic hypercapnia. Eur Respir J 2002;20: 6-11.

6 Ketabchi F, Egemnazarov B, Schermuly RT, Ghofrani HA, Seeger W, Grimminger F, Shid-Moosavi M, Dehghani GA, Weissmann N, Sommer N. Effects of hypercapnia with and without acidosis on hypoxic pulmonary vasoconstriction. Am J Physiol Lung Cell Mol Physiol 2009;297:L977-L983.
7 Kuhr FK, Smith KA, Song MY, Levitan I, Yuan JX. New mechanisms of pulmonary arterial hypertension: role of $\mathrm{Ca}^{2+}$ signaling. Am J Physiol Heart Circ Physiol 2012;302:H1546-H1562.

8 Nakazawa K, Amaha K. Effect of nicardipine hydrochloride on regional hypoxic pulmonary vasoconstriction. Br J Anaesth 1988;60:547-554.

9 Simonneau G, Escourrou P, Duroux P, Lockhart A. Inhibition of hypoxic pulmonary vasoconstriction by nifedipine. N Engl J Med 1981;304: 1582-1585.

10 Devlin JW, Coplin WM, Murry KR, Rengachary SS, Wilson RF. Nimodipine-induced acute hypoxemia: case report. Neurosurgery 2000;47:1243-1246. [Discussion, pp. 1246-1247.]

11 Baker M, Bastin MT, Cook AM, Fraser J, Hessel E II. Hypoxemia associated with nimodipine in a patient with an aneurysmal subarachnoid hemorrhage. Am J Health Syst Pharm 2015;72:39-43.

12 Cotte J, D'Aranda E, Esnault P, Bordes J, Meaudre E. [Nicardipine induced hypoxia: role of hypoxic pulmonary vasoconstriction]. Rev Pneumol Clin 2012;68:221-224.

13 Dennehy KC, Dupuis JY, Nathan HJ, Wynands JE. Profound hypoxemia during treatment of low cardiac output after cardiopulmonary bypass. Can J Anaesth 1999;46:56-60. 